\title{
Ambivalence in Narrative Therapy: A Comparison Between Recovered and Unchanged Cases
}

\author{
António P. Ribeiro, ${ }^{1 \dagger}$ Miguel M. Gonçalves, ${ }^{1 *+}{ }^{*}$ Joana R. Silva, ${ }^{1}$ Andreia Brás ${ }^{1}$ \\ and Ines Sousa ${ }^{2}$ \\ ${ }^{1}$ CIPsi - Psychology Research Center, Psychotherapy and Psychopathology Research Unit, School of Psychology, \\ University of Minho, Braga, Portugal \\ ${ }^{2}$ Department of Mathematics and Applications, University of Minho, Braga, Portugal
}

\begin{abstract}
Research on the identification of poor outcome predictors is crucial for the prevention of therapeutic failure. Previous research suggests that clients' persistent ambivalence is one possible path to unsuccessful psychotherapy. The present study analyses ambivalence-here operationalized as return-tothe-problem markers (RPMs) - in five recovered and five unchanged cases of narrative psychotherapy for major depression. The results suggest that both recovered and unchanged cases presented a similar proportion of RPMs at baseline and a decreasing pattern of these ambivalence markers throughout therapy. However, the decreasing was more accentuated in recovered than in unchanged cases, and at the end of the treatment, the proportion of RPMs of the unchanged cases was significantly higher. The results are discussed in light of previous research on ambivalence in psychotherapy, focusing on the meaning of ambivalence and its clinical implications. Copyright $\odot 2015$ John Wiley \& Sons, Ltd.

Key Practitioner Message:

- Ambivalence towards change, here operationalized as RPMs, seems to be a common process in both recovered and unchanged cases, perhaps signalling the uncertainty and anxiety that change may elicit.

- Although the number of RPMs decreased in both the recovered and unchanged cases, this reduction was significantly higher in the recovered group. Moreover, at the end of therapy, the recovered group revealed a significantly lower proportion of RPMs than the unchanged group, suggesting that ambivalence resolution (or lack thereof) may play a determining role in the therapy's evolution and outcome.

- RPMs in later stages of therapy may be operationalized as 'red flags' for the therapist to acknowledge the client's stuckness and adapt his or her intervention efforts, turning these instances into developmental opportunities.
\end{abstract}

Keywords: process research, narrative therapy, ambivalence, return-to-the-problem markers

As emphasized by Lambert (2007), the identification of poor outcome predictors is crucial for the prevention of therapeutic failure. Most studies have pursued this goal through the analysis of the factors associated with clients' dropout, non-adherence or non-response to therapy and resistance (e.g., Beutler, Harwood, Michelson, Song, \& Holman, 2011; De Panfilis et al., 2012; Taylor, Abramowitz, \& McKay, 2012). In the present study, we contribute to the understanding of the processes through which psychotherapy fails to achieve its goal of clients' change.

In the last few years, we have developed a model that suggests that one possible path to unsuccessful

${ }^{*}$ Correspondence to: M. Goncalves, Applied Psychology, Psychotherapy and Psychopathology Research Unit, CIPsi, School of Psychology, University of Minho, Braga, Portugal.

E-mail: mgoncalves@psi.uminho.pt

${ }^{+}$António P. Ribeiro and Miguel M. Gonçalves are both first author of this article. psychotherapy is clients' persistent ambivalence, here conceptualized as a form of problematic self-stability that can be maintained throughout therapy by a cyclical movement between two opposing parts of the self: the emergence of unique outcomes (White \& Epston, 1990) (here termed as innovative moments; see Gonçalves, Matos, \& Santos, 2009; Gonçalves, Ribeiro, Mendes, Matos, \& Santos, 2011) and the devaluation of their change potential by a return to the previous problematic pattern (termed problematic self-narrative). The clients' problematic selfnarratives may be described as the usual and problematic ways of understanding the world, and innovative moments (IMs) - an empirical application of the concept of unique outcomes-may be seen as moments (including thoughts, feelings or actions) in the therapeutic dialogue when clients act, feel or think differently, thus challenging their problematic self-narratives. For instance, if the problematic self-narrative is characterized by self-devaluation, an IM would be all the instances in which the client values 
him or herself as person. Hypothesis-testing studies (Gonçalves et al., 2012; Matos et al., 2009; Mendes et al., 2010, 2011) and case studies (Alves, Mendes, Gonçalves, \& Neimeyer, 2012; Gonçalves et al., 2010, Mendes et al., 2010; Ribeiro, Bento, Salgado, Stiles \& Gonçalves, 2011; Santos, Gonçalves \& Matos, 2011; Santos, Gonçalves, Matos \& Salvatore, 2009) have suggested that IMs can be reliably identified through the IMCS (Gonçalves, Ribeiro, Mendes et al., 2011) and are associated with psychotherapeutic change across different models of brief therapy. ${ }^{1}$ That is, IMs emerge more in recovered than in unchanged cases.

When a client produces an IM, and ambivalence towards change emerges, the dominance of the problematic self-narrative could be reestablished, reducing the change potential of the IM. The main idea is that after the emergence of an IM, there are two very different possibilities: amplifying the change or devaluing and neutralizing change. For example, the client could state, 'I'm feeling really less depressed lately' (which would be an IM), and neutralize the change potential present in the IM by trivializing the exception, 'But I'm still a depressed person. After all, it's in my genes'. Another possibility is that the change potential is amplified, as in the following example: 'I'm feeling really less depressed lately (IM), and this feels like a burden that slowly is disappearing from my life. This feels really good.'

We have previously studied this form of ambivalence in emotion-focused therapy (EFT) for depression (Ribeiro, Mendes, Stiles, Sousa \& Gonçalves, 2013) and in narrative therapy (NT) with women who were victims of intimate violence (Gonçalves et al., 2011). In the study of Gonçalves et al. (2011), RPMs were more likely to occur in unchanged than recovered cases, thus illustrating how this ambivalent movement between IMs and the problematic self-narrative may interfere with therapeutic outcome. On the contrary, in Ribeiro et al.'s (2013) study, it was found that the global proportion of RPMs throughout treatment did not significantly differ between recovered and unchanged cases. However, in this sample, the percentage of RPMs significantly decreased throughout therapy in the recovered group, whereas it remained stable and high in the unchanged group. The present study aims to replicate and extend these studies by analysing ambivalence in 10 cases (five recovered and five unchanged cases) ${ }^{2}$ of NT for major depression that were previously analysed with the IMCS (Gonçalves, Ribeiro, Mendes et al., 2011) by Gonçalves and colleagues (2013).

\footnotetext{
${ }^{1}$ Outcome group defined according to the Reliable Change Index (RCI; Jacobson \& Truax, 1991)

${ }^{2}$ These studies have identified five types of IMs that correspond to different narrative processes: action, reflection, protest, reconceptualization and performing change (for further details, see Gonçalves, Ribeiro, Mendes, et al., 2011).
}

\section{Resistance, Ambivalence, and the Return-to-the-Problem Markers}

Resistance has been considered to exert a determinant role in the therapeutic process and outcome (Wachtel, 1999). Nevertheless, there are few empirical studies on this process, and the considerable methodological differences among the existing studies, chiefly regarding the operationalization and measurement of the construct of resistance, make it difficult to generalize results and to clearly grasp the associations between resistance and therapeutic outcome (see Mahalik, 2001). The term 'resistance' was first introduced within psychoanalytic theory (Beutler et al., 2011; Wachtel, 1999), but it has spread to nearly all theoretical traditions, and its definition and the mechanisms involved in it, as well as the guidelines to overcome it, vary substantially across theoretical and therapeutic approaches (see Beutler, Moleiro \& Talebi, 2002).

However, most of these models-psychodynamic (Messer, 2002), cognitive (Newman, 2002), interpersonal (Van Denburg \& Kiesler, 2002) and humanistic/experiential (Engle \& Arkowitz, 2008; Engle \& Holiman, 2002)—accept that resistance may act as a form of self-protection used by clients to deal with the instability, insecurity or anxiety that frequently arises from the demanding circumstances that occur during treatment. Change usually implies the abandonment of well-established working patterns (equated in this article with the concept of problematic self-narrative), a process that may be quite threatening and even disturbing for the clients (Hayes, Laurenceau, Feldman, Strauss, \& Cardaciotto, 2007).

This perspective of resistance as a 'normal byproduct of the process of changing complex behaviors' (Moyers \& Rollnick, 2002, p. 187) has been emphasized by motivational interviewing, which in the last few years has presented an empirically supported line of intervention specifically designed to reduce the resistance that frequently arises in the initial phases of psychotherapy. Thus, the bottom line is that when a process of change threatens self-stability, clients may waver between the maintenance of the status quo and attempting to change it. In this sense, resistance may be translated into a state of ambivalence in which the clients aim to attain some form of balance between stability (i.e., problematic self-narrative) and change (i.e., innovative moments).

Across the literature, ambivalence is often described as a way of expressing resistance that implies some form of internal conflict between two opposing tendencies of behaving, thinking or feeling (Engle \& Arkowitz, 2008). In other words, there is an 'approach-avoidance' intrapersonal debate in which the clients are simultaneously attracted and repulsed by a given object. Thus, it seems clear that although different theoretical models have presented slightly different formulations of resistance, anchored on their main structural constructs, there are also 
some common or cross-sectional tenets, like the idea that the client has two opposed positions, one favouring change and another one favouring stability. Despite the empirical evidence for the association between resistance and poor therapeutic outcomes (Beutler, Rocco, Moleiro \& Talebi, 2001), some clinicians argue that resistance may constitute an opportunity for change as a marker of an important therapeutic moment (Mahalik, 2001). Research on alliance ruptures has reached similar conclusions, revealing that although the increased frequency of ruptures is associated with poor therapeutic outcomes, the successful repair of these ruptures is associated with good therapeutic outcomes (Safran, Muran \& EubanksCarter, 2011). Consistent with these findings, Patton, Kivlighan and Multon (1997) reported that clients with a good therapeutic outcome were more likely to present a low-high-low pattern of resistance across therapy, although they also reported that resistance tended to decrease throughout therapy, which is clearly consistent with the view that resistance is not necessarily problematic and may in fact become an ally towards change as long as it is adequately overcome during treatment (Wachtel, 1999). Thus, analysis and further understanding of potential resistance markers across therapy is crucial for its early identification and successful resolution (Beutler et al., 2001; Westra et al., 2012).

Based on the aforementioned considerations, it is not difficult to anticipate that the emergence of IMs, as new ways of thinking, acting, feeling and relating, may elicit feelings of uncertainty in clients and thus threaten their self-stability. Hence, when change happens, a discontinuity needs to be resolved (Ribeiro \& Gonçalves, 2010), and the anxiety generated by the change may lead to a selfprotective response that 'distorts, denies or inadequately symbolizes' this discrepant experience (Engle \& Arkowitz, 2008, p. 391). In this sense, self-stability is maintained through the avoidance of internal contradiction or discrepancy, leading to a suppression of innovative ways of feeling, thinking or acting that may emerge (IMs). Following this perspective, it is plausible to assume that throughout treatment, clients may oscillate between the elaboration of IMs that temporarily break with the dominance of the problematic self-narrative and a return to the problematic self-narrative that allows them to reduce the discrepancy created by innovation emergence (IMs). In this repetitive process, expressions of the problematic self-narrative and IMs act as opposing self-positions in a vicious cycle (Figure 1). A similar process is described in narrative therapy literature by Gustafson (1992) that argues that 'these [dominant] stories seem inescapable because what is viewed as the only alternative (the shadow story) turns out to be a loop that reintroduces the main line' (Omer and Alon, 1997, p. 47). Gonçalves, Matos \& Santos (2009) suggested that some IMs can operate as shadow narratives (Gustafson, 1992), allowing a temporary release

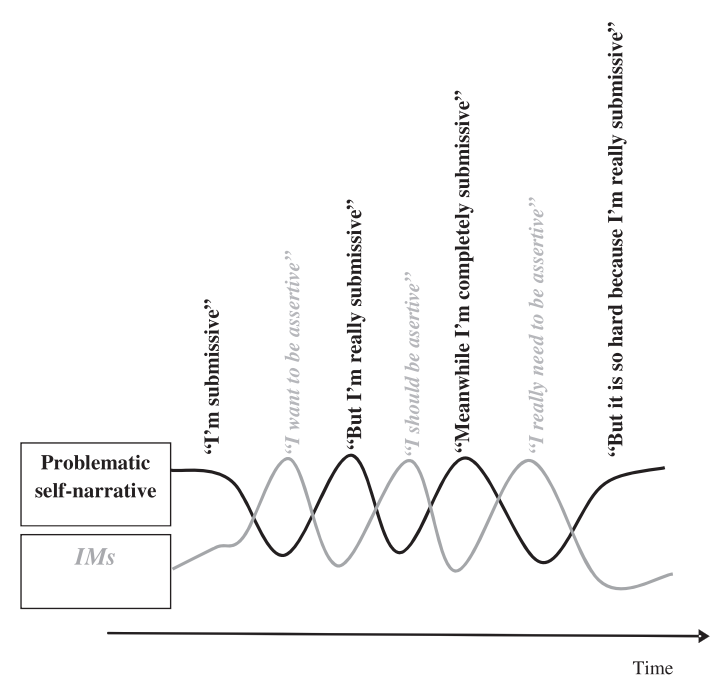

Figure 1. Ambivalence throughout the therapeutic process (adapted from Gonçalves et al., 2011)

from the problematic narrative but facilitating a return to it.

This persistent expression of two opposing aspects of the self, which pull the clients towards distinct directions but allows for the maintenance of the person's status quo or problematic self-narrative, may be conceptualized as a way of resisting change (Ribeiro et al., 2013).

\section{Clinical Illustration}

In order to clarify the constructs of IM and RPM for those who are not well-versed in these concepts and make the results clinically meaningful, we present below a clinical vignette illustrating a therapist-client dialogue including several IMs-RPMs interaction.

Gisela, a PhD student in her twenties, was an unchanged case drawn from the Narrative Therapy sample under analysis in this study (specifics of the sample will be presented in the Method section). Her depression was related to the feeling that she was not happy in her marriage but also feeling that she was unable to separate herself from her husband, as she feared being alone. Gisela often expressed her wish to have a divorced and reported events that mirrored her movement towards this preferential future narrative but also expressed her feelings of fear, hopelessness and helplessness returning to the problematic narrative.

In session 3 from which the excerpt below was drawn, the therapists invited the client to identify 'resources' in her past that she could use to in problematic contexts (which is part of the Narrative Therapy protocol), reviewing events in the past in which she saw herself as 
a strong woman and felt able to fight for a better life. The client accepted the therapist's invitation and elaborated an IM, by acknowledging how powerful she use to be ('I used to have a lot of strength to fight for a better life!') and stating her strong wish to recuperate that strength, as well as the control over her life ('I want that strength back'). However, immediately after, she elaborated an RPM, by expressing 'but I just don't know how to do it, I don't know how to start, I don't know what to do!'

The therapist then invited the client to imagine how the next week would be if she got her strength back. This type of hypothetical question is often used in Narrative Therapy when clients have difficulty identifying unique outcomes in their present lived experience and paves the way for present and future unique outcomes to emerge (Freedman \& Combs, 1996, p. 99). Once again the client accepted the therapist intervention, elaborating an IM, by detailing in which ways her life could be different ('I would be myself and put myself first instead of worrying what other people think about me!'). Similarly to what happened in the previous turn, the client then said 'but I keep worrying about it and that makes me feel bad!', which is in line with her problematic self-narrative and hence constitutes a RPM.

\section{Session 3}

Client (C): I used to have a lot of strength to fight for a better life! [referring to how hard she used to work as a student] I used to be moved by the wish of giving myself and my sons a better life than my parents had...and to make my parents happy (...) and I want that strength back [IM], but I just don't know how to do it, I don't know how to start, I don't what to do! [RPM]Therapist (T): How would the next week be if you recovered that strength? C: Things would be very different...I would be more assertive and would not accept his behaviors [referring to her husband's affairs] ...I would be myself and put myself first instead of worrying what other people think about me! I am not doing nothing wrong [IM], but I keep caring about it and that makes me feel bad! [RPM]

\section{Research questions for the current study}

1. Does the unchanged cases present a globally (i.e., across treatment) higher percentage of RPMs than the recovered cases?

2. Does the probability of RPMs decrease throughout treatment in the recovered cases but not in the unchanged cases?

\section{METHOD}

\section{Clients}

This sample was drawn from a broader group of clients participating in a major outcome study (Lopes et al., 2013) that was designed to compare narrative therapy (NT) with cognitive behavioural therapy (CBT). The selection of participants for this broader project relied on the following inclusion criteria (1) having a major depressive disorder according to the Diagnostic and Statistical Manual of Mental Disorders (DSM-IV; American Psychiatric Association, 2000) and (2) the willingness to provide written informed consent, to answer the questionnaires and to allow the researcher to videotape the sessions. Participants were excluded if they presented at least one of the following characteristics: (a) any Axis II diagnosis, (b) any other concurrent Axis I disorder that might be the main focus of clinical attention (e.g., substance-related disorders, sexual disorders and eating disorders), (c) severe suicidal ideation, (d) psychotic symptoms or (e) bipolar disorder. Clients with anxiety complaints or a secondary anxiety disorder were not excluded if the anxiety was not considered a primary complaint (e.g., panic disorder).

Within this project, clients received individual psychotherapy sessions in a Portuguese university clinic. Sessions had a mean duration of $1 \mathrm{~h}$ and were provided at no charge, scheduled once a week from sessions 1 to 16 and every 2 weeks from sessions 17 to 20 , for a maximum of 20 sessions (plus follow-up at 1, 3, 6 and 12 months). Clients for whom more treatment sessions were recommended were then referred to other therapists from the clinic or to other mental health services to continue treatment.

After the intake, clients were assigned to NT (White \& Epston, 1990) or to CBT (Beck, Rush, Shaw \& Emery, 1979). However, the present study only targeted clients who received NT. Of a total of 34 cases followed in NT, 14 were dropouts $(41.2 \%)$ and 20 were completers $(58.8 \%)$. Of these 34 cases, only 10 were randomly selected to be integrated into the current study's sample: five cases meeting the criteria of recovered cases and five unchanged cases, based on Jacobson and Truax (1991). Thus, two conditions must have been met at the end of the treatment for the recovered group (a) clients moved from a dysfunctional to a functional range, and (b) the change should be reliable, that is, greater than the Reliable Change Index (RCI) for the respective measure. The unchanged group integrated cases in which these two conditions were not met. The RCI analysis was conducted based on the prepost therapy scores on both the Beck Depression Inventory II (BDI-II; Beck, Steer, \& Brown, 1996) and the Outcome Questionnaire (OQ-45.2; Lambert et al., 1996). The differences in the BDI and OQ-45.2 pretreatment to posttreatment scores for the recovered and the unchanged cases are presented in Table 1. 
Table 1. BDI and OQ-45 scores for recovered group and unchanged group

\begin{tabular}{|c|c|c|c|c|c|c|}
\hline & $\begin{array}{c}\text { Pre-test } \\
\text { BDI }\end{array}$ & $\begin{array}{l}\text { Post-test } \\
\text { BDI }\end{array}$ & $\begin{array}{l}\text { Improvement } \\
\text { in the BDI }\end{array}$ & $\begin{array}{l}\text { Pre-test } \\
\text { OQ-45 }\end{array}$ & $\begin{array}{c}\text { Post-test } \\
\text { OQ-45 }\end{array}$ & $\begin{array}{l}\text { Improvement } \\
\text { in the OQ-45 }\end{array}$ \\
\hline \multicolumn{7}{|c|}{ Recovered } \\
\hline \multicolumn{7}{|c|}{ Group } \\
\hline Case 1 & 41 & 3 & 38 & 111 & 16 & 85 \\
\hline Case 2 & 22 & 2 & 20 & 80 & 62 & 18 \\
\hline Case 3 & 28 & 7 & 21 & 89 & 26 & 63 \\
\hline Case 4 & 22 & 2 & 20 & 89 & 14 & 75 \\
\hline Case 5 & 26 & 6 & 20 & 64 & 39 & 25 \\
\hline \multicolumn{7}{|c|}{ Unchanged } \\
\hline \multicolumn{7}{|c|}{ Group } \\
\hline Case 6 & 30 & 33 & -3 & 97 & 95 & 2 \\
\hline Case 7 & 37 & 31 & 6 & 111 & 109 & 2 \\
\hline Case 8 & 48 & 45 & 3 & 122 & 115 & 7 \\
\hline Case 9 & 17 & 20 & -3 & 90 & 75 & 15 \\
\hline Case 10 & 26 & 28 & -2 & 85 & 97 & -12 \\
\hline
\end{tabular}

There were no significant differences between the recovered and unchanged cases regarding the levels of symptom severity at pretreatment on the BDI and the OQ-45.2. Additionally, the two groups did not differ significantly in the number of therapy sessions received throughout the treatment.

Of the 10 clients in this sample, seven were women and three were men (age range $=22-64$ years, $M=41.00$, $S D=14.97)$. Clients completed an average of $18.70(S D=$ 1.83) sessions. Four clients were single, three were married, two were divorced, and one was widowed. All clients had completed at least the ninth grade, but some had up to 24 years of academic education $(M=13.90, S D=5.07)$. Regarding their professional situations, four clients were unemployed, two were professionally active, two were students and one was retired. Their socioeconomic levels, assessed by the Graffar index (Graffar, 1956), ranged from 8 (Level I, high scale) to 16 (Level III, medium scale). These demographic characteristics were not significantly different for clients in the recovered and unchanged groups.

\section{Therapist}

These 10 clients were treated by the same therapist, who at the time of the study was a PhD student in clinical psychology and had 7 years of experience in psychotherapy. The therapist had 3 years of experience in narrative therapy and had received extensive training on a manual of narrative intervention based on the model of White and Epston (1990). The manual involved three main phases and was flexible enough for the therapist to attend to the clients' idiosyncratic characteristics and individual progress during the therapy: (1) deconstruction of the problematic selfnarrative (e.g., externalization, reauthoring conversations and social reactivation of conversations), (2) reconstruction of the alternative/emergent self-narrative (e.g., working on the expansion of unique outcomes) and (3) consolidation of the alternative/emergent self-narrative and finalization (e.g., documenting the process of change, social validation and defining ceremonies). Objectives and strategies for the follow-up sessions were also defined within the manual.

The first author of the manual also worked as a supervisor throughout the project, meeting regularly with the therapist to ensure his adherence to the narrative model of intervention. At the end of the therapeutic process, the therapist's adherence to the narrative therapeutic model was assessed according to the Adherence and Competence Scale for Narrative and Cognitive-Behavioural Therapy (ACS-N-CBT; Gonçalves, Bento, Lopes, \& Salgado, 2009). The results revealed this therapist's adherence to be adequate (Lopes et al., 2013).

\section{Measures}

Beck Depression Inventory II (BDI-II; Beck, Steer, E Brown, 1996)

The BDI is a 21-item self-report instrument assessing symptoms of depression. The items are rated on a fourpoint Likert scale, from 0 to 3 , with total scores ranging from 0 to 63 . The results of the BDI-II internal consistency $(\alpha=0.91$ in Steer, Brown, Beck, \& Sanderson, 2001; $\alpha=0.89$ in Lopes et al., 2013) and construct validity (Beck et al., 1996; Steer et al., 2001) have proved to be highly satisfactory. Validation for the Portuguese population has demonstrated similar results to those found for the American population (Campos \& Gonçalves, 2011; Coelho, Martins, \& Barros, 2002). Because the Reliable Change Index (RCI; Jacobson \& Truax, 1991) could not be found across Portuguese studies, normative data gathered from metaanalyses of diverse samples (Seggar, Lambert \& Hansen, 2002) were used to calculate the proportion of clinical change $(\mathrm{RCI}=8.46$; cut-off score $=14.29)$. 
OQ-45.2 (Lambert et al., 1996)

The OQ-45.2 is a well-known self-report instrument that allows the monitoring of clients' progress and clinical conditions when administered repeatedly throughout therapy. It is also commonly administered at the end of treatment to assess the clients' clinical outcome. It comprises 45 questions concerning not only psychological distress but also interpersonal relations and the social role of the clients. Excellent values of internal consistency have been reported for Portuguese $(\alpha=0.89)$ and non-Portuguese samples (De Jong et al., 2007; Lambert et al., 1996). Three-week test-retest reliability indicated good temporal stability (Pearson $r=0.84$; Lambert et al., 1996).

\section{Innovative Moments Coding System (IMCS; Gonçalves} et al., 2011)

The IMCS has been previously used in several studies across different clinical problems and/or models of intervention (Alves, et al., 2012; Gonçalves et al., 2012; Matos et al., 2009), and it has proved to be reliable. The average interjudge percentage of agreement on overall IM salience (the proportion of the session occupied by each IM) ranged from $84 \%$ to $94 \%$ (calculated as the overlapping of the salience identified by both judges divided by the total salience identified by either judge; Gonçalves, Ribeiro, Mendes et al., 2011).

\section{Return-to-the-Problem Coding System (RPCS; Gonçalves} et al., 2011)

As described in the Return-to-the-Problem Coding System Manual (Gonçalves, Ribeiro, Santos, Gonçalves, \& Conde, 2009), this is a qualitative system that analyses the reemergence of the problematic self-narrative (through the emergence of RPMs) immediately after the emergence of an IM or within the client's first speaking turn after the therapist's first intervention following the IM emergence. Gonçalves et al. (2011) reported reliable agreement between judges on RPM coding, with a Cohen's $k$ of 0.93 .

\section{Procedures}

\section{IM Coding and Reliability}

After the clients provided written consent, the psychotherapeutic sessions were videotaped and transcribed. Each session from the 10 selected cases was coded using the IMCS (Gonçalves et al., 2013). The coding procedure required data analysis by two different coders, who were unaware of the cases' outcomes. For the current sample, two researchers ( $\mathrm{PhD}$ students) independently coded the entire sample. Disagreements were resolved through consensus after regular discussion meetings. For a detailed description of the IM training and coding process, please see Gonçalves, Ribeiro, Mendes and colleagues (2011).
Reliability indexes were computed for the entire sample, resulting in an agreement on overall IMs salience of $89.9 \%$.

\section{RPM Coding and Reliability}

For the present study, two pairs of judges participated in the RPM coding procedure: Judge A (first author) and Judge B (third author) coded five cases, and Judge C (fourth author) and Judge B coded five cases. All coders were unaware of the cases' outcome; Judges A and B were expert coders, and Judge $C$ was trained before coding the present sample. Training in the RPM coding system involves the following steps: (1) reading the RPCS manual (Gonçalves et al., 2009) and (2) coding RPMs in two workbooks that include transcripts of all IMs from one psychotherapy case and subsequent discussion of discrepancies with a skilled RPM judge. At the end of this training process, the judge's codings are compared with those of expert judges. Judges are considered reliable if they achieve a Cohen's $k$ higher than 0.75 , which was the case here.

RPM coding comprised two sequential steps: (1) independent coding and (2) resolving disagreements through consensus. The judges coded the entire sample (180 sessions), analysing IMs previously coded by Gonçalves et al. (2013) for the presence of RPMs, following the RPCS manual. The sessions were coded from the transcripts in the order in which they occurred. The reliability of identifying RPMs, assessed by Cohen's $k$, was 0.89 based on the initial independent coding of a sample of 5257 IMs. Throughout the coding process, the three judges met after coding the first two sessions, and if the agreement was high (as was always the case), they would meet again after completing the coding for that particular case. Across these meetings, the differences between coding were identified and then resolved through consensual discussion. This interactive and collaborative procedure allowed the judges to integrate each other's strengths, which facilitated the coding of subsequent sessions (cf. Brinegar, Salvi, Stiles \& Greenberg, 2006).

\section{RESULTS}

In the following analysis, given the substantial variation in the number of IMs identified across cases, the percentage of RPMs was computed (frequency of IMs with RPMs/total frequency of IMs*100), and this percentage was the measure used below (instead of the frequency of RPMs).

1. Does unchanged cases present a globally (i.e., across treatment) higher percentage of RPMs than the recovered cases?

To address this question, a Mann-Whitney test was used. The results revealed no significant differences between 
the recovered $(\mathrm{M}=22.93 ; S D=6.67)$ and unchanged groups $(\mathrm{M}=24.57 ; S D=7.94)$ in the percentages of IMs followed by RPMs, $U=12.00, p=1.00$.

2. Does the probability of RPMs decrease throughout treatment in the recovered, but not in unchanged cases?

This question was tested with a Generalized Linear Model (GLM) analysis. A GLM analysis allows for the construction of a regression model of probabilities as a linear function of the explanatory variables through the logit link function (this function allows outcomes to vary between 0 and 1) (McCullagh \& Nelder, 1989). Significance levels were placed at $\alpha=0.05$. The GLM model is similar to a regression analysis with a longitudinal structure, which means that instead of having just one measure of the outcome, we have outcome measures throughout treatment for each session (e.g., RPMs for each session). Furthermore, a subject-specific random effect was included to take into account variability among individuals, given that we expected that measurements (RPMs) from the same client would be correlated.

Thus, the GLM model used to test this hypothesis assumed the proportion of RPMs as the response variable and time (from the first to the last session) and therapy outcome (recovered or unchanged) as explanatory variables. As seen in Figure 2, at baseline (the initial phase of therapy), the estimated probability of RPMs was $23.7 \%$ in the recovered group and $27.7 \%$ in the unchanged group. Despite the slightly higher value found for the probability of RPMs in the unchanged group at baseline, this difference was not statistically significant, $p=0.67$. Moreover, it is also noticeable (Figure 2) that as the treatment progressed there was a decrease in the likelihood

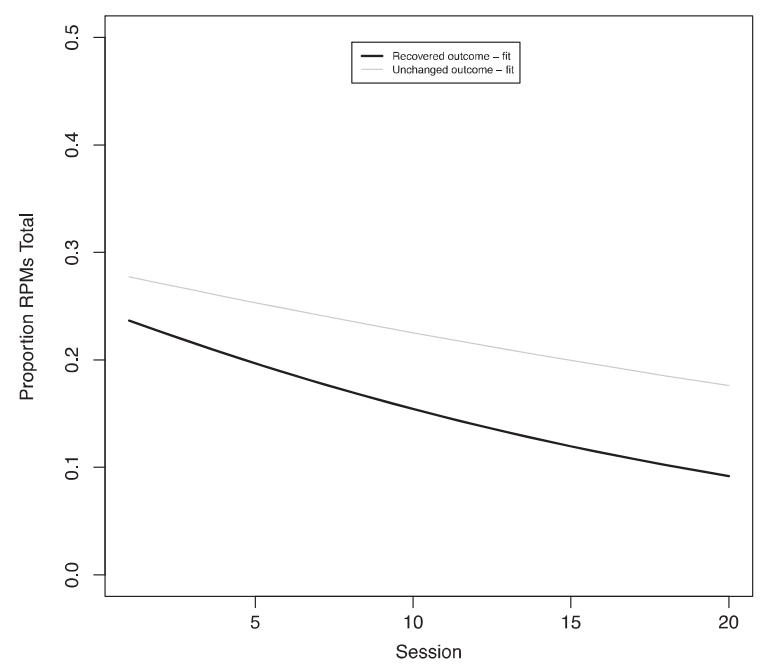

Figure 2. Evolution of RPMs throughout the treatment of RPM occurrence in both groups. However, the evolution of the two groups proved to be significantly different, $p=.04$, effect size $R^{2}=0.78$, with a greater decrease found in the recovered group. At the last session, the percentage of RPMs was higher in the unchanged group $(17.6 \%)$ than in the recovered group $(9.2 \%)$, and these probabilities were significantly different, $p=0.04$.

\section{DISCUSSION}

The results revealed that overall, that is, taking all the sessions from each case into account, there were no differences in RPMs between recovered and unchanged cases. These results are congruent with the proposal of Ribeiro et al. (2013) suggesting that RPMs as markers of ambivalence towards change may be a relatively common phenomenon both in good and poor outcome cases, perhaps signalling the uncertainty and anxiety that change may elicit. It has been suggested that the demanding nature of the therapeutic work may result in ambivalence or resistance towards novelty emergence, being experienced by virtually all clients during more demanding times of their change process (Engle \& Arkowitz, 2008; Moyers \& Rollnick, 2002; Wachtel, 1999). This ambivalence is probably associated with the need for self-protection when facing a rupture of their usual ways of functioning. These old and rigid patterns of functioning caused the clients suffering but were nevertheless more familiar and predictable, and as such safer than any change that is by its nature highly unpredictable. Thus, the identification of ambivalence signs in most of the clients in this sample, regardless of their final outcome, reinforces the importance of studying the phenomena of resistance and ambivalence in psychotherapy (Wachtel, 1999).

However, despite this resemblance in the overall frequency of RPMs in recovered and unchanged cases, differences between groups emerged when we take a longitudinal perspective. Although the number of RPMs decreased in both the recovered and the unchanged cases, this reduction was significantly higher in the recovered group. Moreover, at the end of therapy, the recovered group revealed a significantly lower proportion of RPMs than did the unchanged group. This result is consistent with the theoretical assumptions presented before, suggesting that the dominance of RPMs, signalling a persistence of ambivalence towards change, may contribute to a negative evolution of psychotherapy. We suggest that in recovered clients the reduction of RPMs throughout treatment may be associated with a progressive, more effective integration and consolidation of the new emergent self-narrative. Thus, while recovered and unchanged cases started at a similar level of RPMs production, in recovered cases their reduction is faster, which suggest that ambivalence at the beginning of therapy is not necessarily an unsurpassable 
obstacle. This suggestion is also supported by the study by Patton and colleagues (1997) that found a low-high-low pattern of resistance during therapy for good outcome clients. In sum, what may determine ambivalence's association with a good or poor therapeutic outcome could be how it is adequately overcome during the treatment.

One intriguing result, which was not found in previous studies that used this methodology (Gonçalves et al., 2011; Ribeiro et al., 2013), was the decreasing pattern of RPMs also in unchanged cases. In previous studies, unchanged cases remain with high RPMs emergence along the treatment, sometimes even increasing their presence. We offer two possible explanations for this pattern, which are not necessarily incompatible. First, this decrease might reflect some improvement also in the unchanged cases, suggesting that perhaps with more time of treatment, and with the proper therapeutic tools (e.g., motivational interviewing), these cases, or at least some of them, could become recovered. A second interpretation is more interactional. Perhaps the therapist confronted with an absence of reduction of ambivalence towards change, and a related stability in the clinical symptoms, adjusted his own expectations and decreased the pressure to change. In fact, the role of the therapist in the emergence and evolution of clients' resistance during therapy is well documented (Engle \& Arkowitz, 2008; Moyers \& Rollnick, 2002; Westra et al., 2012). Thus, we hypothesize that after some sessions without successful outcomes, when therapists see their attempts to defy the problematic selfnarrative systematically frustrated, they may reduce their expectations of their clients' change potential. If clients are not challenged, they do not feel threatened and thus do not need to reaffirm their difficulties (the problematic self-narrative), thus reducing the producing of RPMs. Future studies should test this hypothesis.

This study adds to a new research programme on ambivalence (Gonçalves et al., 2011; Gonçalves et al., 2012; Ribeiro et al., 2013), giving additional support to the research findings obtained to date, despite the sample size. Ambivalence towards change, here operationalized as RPMs, seems to be a common process in psychotherapy. Furthermore, it seems clear that its resolution (or lack thereof) may play a determining role in the therapy's evolution and outcome. Thus, we believe that further studies of these markers of ambivalence may contribute to the crucial task outlined by Lambert (2007) of identifying poor outcome predictors in an attempt to prevent therapeutic failure. In particular, RPMs that seem to be maintained and even increased throughout therapy may be operationalized as 'red flags' for the therapist to acknowledge the client's stuckness and adapt his or her intervention efforts, turning these instances into developmental opportunities.

The present study presents some limitations that may constrain the range of interpretations and generalization of the conclusions. In particular, the small size of the sample, the specificity in the clients (only those diagnosed with major depression) and the fact that they were all followed by the same therapist constrain the generalization of results to far-reaching populations. Moreover, considering that psychotherapy is a dyadic relational phenomenon, it would be important to consider the variables associated with the therapist that may contribute to the understanding of how ambivalence processes unfold throughout therapy (Ribeiro et al., 2013). Despite these limitations, the core results replicate the findings obtained with other samples, thus contributing to an increased confidence in these results.

\section{Therapist's Role in Maintenance of Ambivalence: Preliminary Results and Future Studies}

Insofar as resistance is an interpersonal phenomenon, therapist's response to ambivalence may also contribute to the differences between recovered and unchanged cases across sessions. In a recent study, using the EFT sample, Cunha et al. (2012), explored the association between therapist skills-exploration, insight and action (Hill, 2009) - and IMs and found two possibly related results. First, in contrast to recovered cases, in the unchanged cases, therapist use of action skills steadily increased across therapy. Second, insight skills were used more often in all phases of unchanged cases. Cunha et al. speculated that therapists were not able to engage clients as readily in the therapeutic tasks in the unchanged cases and then kept trying to engage them later when it may have been too late, producing the increase in use of action skills. This is probably consistent with higher use of insight skills in unchanged cases leading authors to speculate that in unchanged cases therapists were trying to find some way to help the clients when the more typically prescribed exploration skills were not working. In sum, Cunha et al. found higher levels of therapist directiveness towards change in unchanged cases, which are associated with higher levels of client resistance (Miller, Benefield, \& Tonigan, 1993; Patterson \& Forgatch, 1985; cf. Anderson, KnoblochFedders, Stiles, Ordonez, \& Heckman, 2012).

In an in-depth qualitative study of the therapeutic interaction within IM-RPMs sequences in an unchanged case of Narrative Therapy - Maria, we found that most times, the therapist responded to client's RPMs by challenging. Interestingly, after instances in which the therapist responded to an RPM with a challenging intervention, the client tended to invalidate the therapeutic intervention. There were also instances in which the client only minimally validated therapist's intervention (Ribeiro et al., 2014). These observations converge with previous work in suggesting that when therapists challenge their clients, trying to stimulate or amplify IMs in ways that do not match the 
clients' developmental level, they may unintentionally contribute to the oscillatory cycle between the IMs and the maladaptive self-narrative (Santos et al., 2011) and likely reinforce the dominance of the problematic self-narrative. This might mirror an interpersonal vicious cycle in which the therapist tries to convince the client he or she is changing, and the client (who feels misunderstood) tries to convince the therapist he or she is still in pain (Gergen \& Warhuus, 2007). It is likely that as this cycle goes on, both the client and the therapist might hardening their positions.

In fact, in the case of Maria, the therapist seemingly offered more empathy to clients's IMs than to her problematic self-narrative. Omer and Alon (1997) emphasized that 'to succeed, the new story must be close enough to the client's experience so that [he or] she may view as [his or] her; on the other hand, it must be different enough from the old story, so as to allow new meanings and options to be perceived' (p. 10). The therapist must honour client's experiential reality, empathizing with the client's usual framework of understanding (i.e., problematic self-narrative) and at the same time defy it, empathizing with the potential alternative framework of understanding (i.e., the developing alternative self-narrative expressed in IMs). Further research is needed. Intensive analysis of how therapists responded to RPMs in cases in which RPMs decreased across treatment would support our suggestion.

\section{REFERENCES}

Alves, D., Mendes, I., Gonçalves, M. M., \& Neimeyer, R. A. (2012). Innovative moments in grief therapy: Reconstructing meaning following perinatal death. Death Studies, 36, 795-818. doi:10.1080/07481187.2011.608291

American Psychiatric Association (2000). DSM-IV-TR. Lisboa: CLIMEPSI.

Anderson, T., Knobloch-Fedders, L., Stiles, W. B., Ordonez, T., \& Heckman, B. D. (2012). The power of subtle interpersonal hostility in psychodynamic psychotherapy: A speech acts analysis.. Psychotherapy Research, 22, 348-362.

Beck, A. T., Rush, A. J., Shaw, B. E, \& Emery, G. (1979). Cognitive therapy of depression. New York: Guilford Press.

Beck, A. T., Steer, R. A., \& Brown, G. K. (1996). Manual for the Beck Depression Inventory-II (BDI-II). San Antonio, TX: Psychological Corporation.

Beutler, L. E., Harwood, T. M., Michelson, A., Song, X., \& Holman, J. (2011). Resistance/Reactance level. Journal of Clinical Psychology, 67, 133-142. doi:10.1002/jclp.20753

Beutler, L. E., Moleiro, C., \& Talebi, H. (2002). Resistance in psychotherapy: What conclusions are supported by research? Journal of Clinical Psychology, 58, 207-217. doi:10.1002/jclp.1144

Beutler, L.E., Rocco, F., Moleiro, C.M., \& Talebi, H. (2001). Resistance. Psychotherapy, 38, 431-436.

Brinegar, M. G., Salvi, L. M., Stiles, W. B., \& Greenberg, L. S. (2006). Building a meaning bridge: Therapeutic progress from problem formulation to understanding. Journal of Counseling Psychology, 53, 165-180. doi:10.1037/0022-0167.53.2.165
Campos, R. C., \& Gonçalves, B. (2011). The Portuguese Version of the Beck Depression Inventory-II (BDI-II). European Journal of Psychological Assessment, 27, 258-264.

Coelho, R., Martins, A., \& Barros, H. (2002). Clinical profiles relating gender and depressive symptoms among adolescents ascertained by the Beck Depression Inventory II. European Psychiatry, 17, 222-226.

Cunha, C., Gonçalves, M. M., Hill, C. E., Mendes, I., Sousa, I., Ribeiro, A. P., Angus, L., \& Greenberg, L. (2012). Therapist interventions and client innovative moments in emotionfocused therapy for depression. Psychotherapy, 4, 536-548. doi: 10.1080/10503307.2013.856042

De Jong, K., Nugter, M. A., Polak, M. G., Wagenborg, J. E. A., Spinhoven, P., \& Heiser, W. J. (2007). The outcome questionnaire (OQ-45) in a Dutch population: A cross-cultural validation. Clinical Psychology \& Psychotherapy, 14, 288-301. doi:10.1002/cpp.529

De Panfilis, C., Marchesia, C., Cabrinob, C., Monicib, A., Politib, V., Rossib, M., \& Magginia, C. (2012). Patient factors predicting early dropout from psychiatric outpatient care for borderline personality disorder. Psychiatry Research, 200, 422-429. doi:10.1016/j.psychres.2012.03.016

Engle, D., \& Arkowitz, H. (2008). Viewing resistance as ambivalence: Integrative strategies for working with ambivalence. Journal of Humanistic Psychology, 48, 389-412. doi:10.1177/ 0022167807310917

Engle, D., \& Holiman, M. (2002). A gestalt-experiential perspective on resistance. Journal of Clinical Psychology, 58, 175-183. doi:10.1002/jclp.1141

Freedman, J. \& Combs, G. (1996). Narrative therapy: The social construction of preferred realities. New York: Norton.

Gergen, K., \& Warhuus, L. (2007). Terapia como construção social: Características, reflexões e evoluções. In M. M. Gonçalves \& O. F. Gonçalves (Eds.), Psicoterapia, discurso e narrativa: A construção conversacional da mudança (pp. 29-65). Coimbra: Quarteto.

Gonçalves, M., Bento, T., Lopes, R., \& Salgado, J. (2009). Manual da Escala de Adesão e Competência. Braga, Portugal.

Gonçalves, M. M., Matos, M., \& Santos, A. (2009). Narrative therapy and the nature of 'innovative moments' in the construction of change. Journal of Constructivist Psychology, 22, 1-23. doi:10.1080/10720530802500748

Gonçalves, M. M, Mendes, I., Cruz, G., Ribeiro, A. P., Sousa, I., Angus, L., \& Greenberg, L. (2012). Innovative moments and change in client-centered therapy. Psychotherapy Research, 22, 389-401. doi:10.1080/10503307.2012.662605

Gonçalves, M. M, Mendes, I., Ribeiro, A. P., Angus, L., \& Greenberg, L. (2010). Innovative moments and change in emotion-focused therapy: The case of Lisa. Journal of Constructivist Psychology, 23, 267-294. doi:10.1080/ 10720537.2010.489758

Gonçalves, M. M., Ribeiro, A. P., Mendes, I., Matos, M. \& Santos, A. (2011). Tracking novelties in psychotherapy process research: The innovative moments coding system. Psychotherapy Research, 21, 497-509. doi:10.1080/10503307.2011.560207

Gonçalves, M. M., Ribeiro, A. P., Mendes, I., Silva, J. R., Batista, J., Sousa, M., \& Sousa, I. (2013). Innovative moments in narrative therapy: A comparison between recovered and unchanged cases. Manuscript in preparation.

Gonçalves, M. M., Ribeiro, A. P., Santos, A., Gonçalves, J., \& Conde, T. (2009). Manual for the return to the problem coding system-Version 2. Unpublished manuscript, Braga, Portugal: University of Minho.

Gonçalves, M. M., Ribeiro, A. P., Stiles, W. B., Conde, T., Santos, A., Matos, M., \& Martins, C. (2011). The role of mutual in- 
feeding in maintaining problematic self-narratives: Exploring one path to therapeutic failure. Psychotherapy Research, 21, 27-40. doi:10.1080/10503307.2010.507789.

Gustafson, J. P. (1992). Self-delight in a harsh world. New York: Norton.

Graffar, M. (1956). Une méthode de classification sociale d'echantillons de population. Courrier, 6, 455-59.

Hayes, A. M., Laurenceau, J. P., Feldman, G. C., Strauss, J. L., \& Cardaciotto, L. A. (2007). Change is not always linear: The study of nonlinear and discontinuous patterns of change in psychotherapy. Clinical Psychology Review, 27, 715-723. doi:10.1016/j.cpr.2007.01.008

Hill, C. E., (2009). Helping skills: Facilitating exploration, insight, and action (3rd ed.), Washington, DC: American Psychological Association.

Jacobson, N. S., \& Truax, P. (1991). Clinical Significance: A statistical approach to defining meaningful change in psychotherapy research. Journal of Consulting and Clinical Psychology, 59, 12-19. doi:10.1037/0022-006X.59.1.12

Lambert, M. (2007). Presidential address: What we have learned from a decade of research aimed at improving psychotherapy outcome in routine care. Psychotherapy Research, 17, 1-14. doi:10.1080/10503300601032506

Lambert, M. J., Burlingame, G. M., Umphress, V., Hansen, N. B., Vermeersch, D. A. Clouse, G. C., \& Yanchar, S. C. (1996). The reliability and validity of the Outcome Questionnaire. Clinical Psychology $\mathcal{E}$ Psychotherapy, 3, 249-258. doi:10.1002/(SICI)1099-0879(199612)

Lopes, R., Gonçalves, M., Machado, P. P., Sinai, D., Bento, T., \& Salgado, J. (2013). Narrative therapy vs. cognitive-behavioral therapy for moderate depression: Empirical evidence from a controlled clinical trial. Manuscript submitted for publication.

Mahalik, J. R. (2001). Understanding client resistance in therapy: Implications from research on the counseling process. In G. S. Tryon (Ed.), Counseling based on process research: Applying what we know (pp. 66-80). Boston: Allyn and Bacon.

Matos, M., Santos, A., Gonçalves, M. M., \& Martins, C. (2009). Innovative moments and change in narrative therapy. Psychotherapy Research, 19, 68-80. doi:10.1080/10503300802430657

McCullagh, P., \& Nelder, J. (1989). Generalized linear model. London: Chapman \& Hall.

Mendes, I., Ribeiro, A., Angus, L., Greenberg, L. S., Sousa, I., \& Gonçalves, M. M. (2010). Narrative change in emotionfocused therapy: How is change constructed through the lens of the Innovative Moments Coding System? Psychotherapy Research, 20, 692-701. doi:10.1080/10503307.2010.514960

Mendes, I., Ribeiro, A., Angus, L. Greenberg, L. S., Sousa, I., \& Gonçalves, M. M. (2011). Narrative change in emotionfocused psychotherapy: A study on the evolution of reflection and protest innovative moments. Psychotherapy Research, 21, 304-315. doi:10.1080/10503307.2010.514960

Messer, S. B. (2002). A psychodynamic perspective on resistance in psychotherapy: Vive la resistance. Journal of Clinical Psychology, 58, 157-163. doi:10.1002/jclp.1139

Miller, W. R., Benefield, R. G., \& Tonigan, J. S. (1993). Enhancing motivation for change in problem drinking: a controlled comparison of two therapist styles. Journal of Consulting and Clinical Psychology, 61, 455-461.

Moyers, T. B., \& Rollnick, S. (2002). A motivational interviewing perspective on resistance in psychotherapy. Journal of Clinical Psychology, 58, 185-193. doi:10.1002/jclp.1142

Newman, C. A. (2002). A cognitive perspective on resistance in psychotherapy. Journal of Clinical Psychology, 58, 165-174. doi:10.1002/jclp.1140
Omer, H. \& Alon, N. (1997). Constructing therapeutic narratives. Northvale, N. J.: Jason Aronson.

Patterson, G. R., \& Forgatch, M. S. (1985). Therapist behavior as a determinant for client noncompliance: A paradox for the behavior modifier. Journal of Consulting and Clinical Psychology, 53, 846-851.

Patton, M. J., Kivlighan, D. M., \& Multon, K. D. (1997). The Missouri Psychoanalytic Research Project: Relation of changes in counseling process to client outcomes. Journal of Counseling Psychology, 44, 189-208. doi:10.1037/0022-0167.44.2.189

Ribeiro, A. P., Bento, T., Salgado, J., Stiles, W. B., \& Gonçalves, M. M. (2011). A dynamic look at narrative change in psychotherapy: A case-study tracking innovative moments and protonarratives using state-space grids. Psychotherapy Research, 21, 34-69. doi:10.1080/10503307.2010.504241

Ribeiro, A. P., \& Gonçalves, M. M. (2010). Innovation and stability within the dialogical self: The centrality of ambivalence. Culture \& Psychology, 16, 116-126. doi:10.1177/1354067X09353211

Ribeiro, A.P., Mendes, I., Stiles, W.B., Sousa, I., \& Gonçalves, M.M. (2013). Ambivalence in emotion-focused therapy for depression: The maintenance of problematically dominant self-narratives. Manuscript submitted for publication.

Ribeiro, A.P., Ribeiro, E., Loura, J., Gonçalves, M. M., Stiles, W. B, Horvath, A., \& Sousa, I. (2014). Therapeutic collaboration and resistance: Describing the nature and quality of the therapeutic relationship within ambivalence events using the Therapeutic Collaboration Coding System. Psychotherapy Research, 24, 346-359. 10.1037/a0028259

Safran, J. D., Muran, J. C., \& Eubanks-Carter, C. (2011). Repairing alliance ruptures. Psychotherapy, 48, 80-87. doi:10.1037/00333204.38.4.406

Santos, A., Gonçalves, M. M., \& Matos, M. (2011). Innovative moments and poor-outcome in narrative therapy. Counseling and Psychotherapy Research, 11, 129-139. doi:10.1080/14733140 903398153

Santos, A., Gonçalves, M. M., Matos, M., \& Salvatore, S. (2009). Innovative moments and change pathways: A good outcome case of narrative therapy. Psychology and Psychotherapy: Theory, Research and Practice, 82, 449-466. doi:10.1348/147608309X4 62442

Seggar, L. B., Lambert, M. J., \& Hansen, N. B. (2002). Assessing clinical significance: Application to the Beck Depression Inventory. Behavior Therapy, 33, 253-269. doi:10.1016/S0005-7894(02)80028-4

Steer, R. A., Brown, G. K., Beck, A. T., \& Sanderson, W. C. (2001). Mean Beck Depression Inventory-II scores by severity of major depressive episode. Psychological Reports, 88, 1075-1076. doi:10.2466/pr0.2001.88.3c.1075

Taylor, S., Abramowitz, J. S., Mckay, D. (2012). Non-adherence and non-response in the treatment of anxiety disorders. Journal of Anxiety Disorders. Advance online publication. doi:10.1016/j. janxdis.2012.02.010.

Van Denburg, T.F., \& Kiesler, D.J. (2002). An interpersonal communication perspective on resistance in psychotherapy. Journal of Clinical Psychology, 58, 195-205. doi:10.1002/jclp.1143

Wachtel, P. L. (1999), Resistance as a problem for practice and theory. Journal of Psychotherapy Integration, 9, 103-118. doi:10.1023/ A:1023262928748

Westra, H. A., Aviram, A., Connors, L., Kertes, A., \& Ahmed, M. (2012). Therapist emotional reactions and client resistance in cognitive behavioral therapy. Psychotherapy, 49, 163-172. doi: $10.1037 / \mathrm{a} 0023200$

White, M. \& Epston, D. (1990). Narrative means to therapeutic ends. New York: Norton. 